\title{
International strategic alliances in the Iranian pharmaceutical industry: an analysis of key success and failure factors
}

Hossein Dadfar, Jens Jörn Dahlgaard, Staffan Brege and Bahareh Javadian Arzaghi

\section{Linköping University Post Print}

\section{Tweet}

N.B.: When citing this work, cite the original article.

This is an electronic version of an article published in:

Hossein Dadfar, Jens Jörn Dahlgaard, Staffan Brege and Bahareh Javadian Arzaghi, International strategic alliances in the Iranian pharmaceutical industry: an analysis of key success and failure factors, 2014, Total Quality Management and Business Excellence, (25), 7-8, 812-826.

Total Quality Management and Business Excellence is available online at informaworldTM: http://dx.doi.org/10.1080/14783363.2014.906109

Copyright: Taylor \& Francis (Routledge): SSH Titles http://www.routledge.com/

Postprint available at: Linköping University Electronic Press http://urn.kb.se/resolve?urn=urn:nbn:se:liu:diva-106460 


\title{
International strategic alliances in the Iranian pharmaceutical industry: An analysis of key success and failure factors
}

\author{
Hossein Dadfar ${ }^{1}$, Jens J. Dahlgaard ${ }^{2}$, Staffan Brege ${ }^{3}$ and Bahareh Javadian Arzaghi ${ }^{4}$ \\ Department of Management and Engineering, Linköping University, Sweden ${ }^{1,2,3}$ \\ MBA ProMA Program, Linköping University ${ }^{4}$
}

\begin{abstract}
This study aims to identify key success/failure factors in international strategic alliances (ISAs) in the Iranian pharmaceutical industry, an area which has remained largely unexamined. The literature review, and an expert panel's views, led us to study 33 success factors. These factors, based upon their importance in strategic and structural configuration or the alliance formation process, were grouped as content and process-oriented. A combination of quantitative and qualitative approaches was used for data collection and analysis. The results confirmed that all 33 factors are effective in alliance success, which is an extension of earlier research. The study reveals eight of the most important success factors, and eleven of the most prevalent failure factors. The findings also showed that six out of the eight most important success factors are process-oriented variables. This confirms that trust, mutual understanding and developing strong inter-organizational relationships are extremely important in the success of alliances in the Iranian Pharmaceutical industry. However, eight of eleven failure factors are content-oriented, which means that the failed alliances mainly had problems in the ISAs' strategic and structural design. The qualitative study supports the quantitative results and adds to the high importance of the soft aspect of the alliances' success including: the culture of collaboration, open-mindedness, relationship-building ability, parties' proper knowledge of each other's business culture/working attitudes, and effective communication. Besides, in Iran, the local government and public institutes have significant impact on the success of the alliances. One of the more significant findings that emerged from this study is that "success" can mean different things to different people/partners, so success and failure should be seen from both parties' perspectives.
\end{abstract}

Keywords - Inter-firm collaboration, international strategic alliances, key success and failure factors in strategic alliances, success/failure situations, pharmaceutical industry, Iran.

\section{Introduction}

Many firms choose strategic alliances (SAs) or international strategic alliances (ISAs) to overcome resource and competence limitations. They combine their resources, capabilities and competencies to develop, manufacture and distribute the goods and services of their mutual interests (Townsend, 2003). Thus, alliances are a potential source of sustainable competitive advantage since partners can strengthen the basis of their competition (Prahalad and Hamel, 1990). They often form alliances for entering new markets, reducing new product development costs, sharing risks and resources and delivering value to customers (Hitt et al., 2000). Therefore, SAs have become the backbone of business development (Cravens et al. 2000, Hitt et al., 2000). 
Inter-firm cooperation can have different names because of different descriptions of collaborations, joint ventures, linkages, networks, partnerships, consortia, clusters, etc. (Townsend, 2003). Therefore, the range of definitions for SAs is wide. For example, Dussauge \& Garrette (2000) conceive SAs as a cooperative agreement between two or more independent organizations for improving their competences and performance that neither could acquire individually. Phan (2000) envisions alliances as long-term, trust-based relationships. Porter (1990) perceives SAs as long-term, inter-firm relationships and agreements that go beyond common market transactions. Some SA forms are joint ventures, product and technology licensing, long-term agreements for supply, outsourcing, joint marketing, joint R\&D and other kinds of inter-firm relationships. In this study, we follow Porter's (1990) definition.

The formation of SAs is growing rapidly; e.g., every 90 seconds an alliance is formed, but $60 \%$ of all alliances fail (de Man and Duysters, 2007). The Association of Strategic Alliances Professionals (ASAP) in 2012 reported an increase in the alliance success rate by $50-57 \%$. However, the failure rate $(40-50 \%)$ is still very high, and the failure rate of ISAs is much higher. The pharmaceutical industry also follows the trend; the number of alliance formations is growing while the number of failures is high, and the termination of the alliances is becoming more problematic (Shen-Yu and $\mathrm{Xu}, 2005$ ). The importance of SAs, the growing trend in alliance formation, and the high SA failure rate, all raise the questions of why some alliances are more successful than others, and what are the key success/failure factors in SAs in general and ISAs in particular.

There are many studies available on SAs. However, the studies have been mainly carried out in the context of North America, Europe and large enterprises. Therefore, little has been done on cross-border collaboration with developing countries and SMEs. Furthermore, they have studied success/failures from one party's perspective mainly with a single theoretical lens.

ISAs have become a necessity for the survival of Iranian pharmaceutical firms that use an external sourcing strategy to establish their technology and product platforms (Dadfar, et al. 2013). Furthermore, to stay competitive against low-cost countries, they have to use ISAs to produce branded quality drugs and learn to introduce collaborative culture into their organizations (Dadfar \& Brege, 2012). Despite this, the key success/failure factors of ISAs in the Iranian pharmaceutical industry have remained largely unsearched.

Considering the discussion above, this study attempts to identify the key factors that determine success/failure in international inter-firm strategic collaboration, with a focus on SAs in the Iranian pharmaceutical industry and the following objectives:

1. Identify the success factors affecting the formation if SAs in Iranian pharmaceutical companies.

2. Identify the failure factors affecting the operation of SAs in Iranian pharmaceutical companies

\section{Literature review}

The concept of "strategic alliance" denotes a variety of long-term, inter-firm cooperation (Parkhe, 1991). Examples of common SAs are joint ventures, product and technology licensing, outsourcing agreements, joint marketing, joint R\&D, joint manufacturing, joint innovation and technology development, etc. ISA also refers to international cooperative/collaborative agreements/ventures (Root, 1988), and coalitions or partnerships (Porter and Fuller, 1986; 
Perlmutter and Heenan, 1986). Several theoretical perspectives have contributed to this study, as explained in the coming section.

\section{Strategic Alliance Formation}

The common theoretical perspectives explaining the formation and rationales for creation of SAs are discussed below:

- Transaction-cost theory (TCT): TCT is the most dominant perspective in alliances (Das and Teng, 2000b; Eisenhardt \& Shoonhoven, 1996; Tsang, 1998). The logic of this perspective is cost minimization as a framework for choosing the transaction mode and organizational arrangements. Therefore, alliances are considered the most transaction cost-efficient organizational form (Judge and Dooley, 2006). TCT concerns two types of costs that must be minimized: transaction costs and production costs. According to TCT, alliances fail because of a lack of inter-firm trust and commitment, which leads to opportunistic behavior, and ultimately may lead to the termination of alliances' agreement (Das and Teng, 2000b)?

- Resource-based view (RBV): The RBV explains firms as bundles of all resources, assets and capabilities (Yasuda, 2005). Hence, when a firm needs additional resources that cannot be acquired through market transaction or built internally, alliances arise to create a pool of resources (Glaister, 1996). In the RBV, the rationale for alliance formation is value-creation by bringing resources together (Das and Teng, 2000a).

- Knowledge-based view (KBV): The KBV is the offshoot of organizational learning theory and the RBV that focuses on the knowledge source. Thus, the firms facing high environmental uncertainty can utilize alliances to enhance and speed up organizational learning, reshaping their environment and reducing strategic uncertainty (Grant and Baden- Fuller, 2004).

- Network and inter-organizational perspective: The Network perspective explains the connections of the parties' activities and resources in the alliances' networks (Mort and Weerawardena, 2006). Likewise, inter-organizational theory focuses on cooperative interaction and the dynamic relationship between the parties. It explains alliances in terms of "soft issues" like trust in the interpersonal and inter-organizational relationship (Dyer and Singh, 1998). Access to information, resources, markets and technology are the main motives for engaging in inter-organizational alliances (Gilmore, et al. 2006). Moreover, the increasing number of partnerships leads to a network of inter-firm collaboration, which requires partnership management (Chung, Singh \& Lee, 2000; Duysters et al., 1999).

- Management and leadership theory: This group of theories focuses on the role of key executives' commitment to alliance formation (Eisenhardt and Schoonhoven, 1996).

Alliance as a Process: The inter-firm cooperation can be understood as a five-phase process (Marxt and Link, 2002), as follows:

- Initiation phase: Includes necessary strategic analysis for choosing SAs as instruments to achieve intended goals.

- Partner Selection developing profile: Gathering information and selection of a partner based on the profile, acquisition and persuasion of the partner.

- Designing the partnership: Writing down the alliance contract. 
- Implementation of the partnership: Keeping eyes on SA operation and regular improvement.

- Termination: Making an evaluation at each project end and ensuring learning/experiences.

\section{Success and Failure in Alliances}

Critical success factors refer to variables that meaningfully influence success (Hoffmann and Schlosser, 2001). However, there is no common agreement on critical success factors and successful cooperation. Still, Marxt and Link (2002) maintain that even though the original objectives cannot be reached, the cooperation may be called successful if new business ideas are generated.

Some studies consider an alliance's durability as a parameter for success; others measure its contribution to improving the strategic position or the competitiveness of the allied firms (Fontanari, 1995). Besides the degree of goal achievement, success can be the positive feeling of cooperation as well as the revenues as a whole. In short, Marxt and Link (2002), Fontanari (1995), and Sheng- Yu and Xu (2005) affirm the alliances' success and success/failure factors as:

- Achievement of the original objectives

- Revenues for the cooperation partners as a whole

- Organizational learning

- Subjective personal feelings

- Alliance's durability

- Improving the strategic position or competitiveness of firms

- Value of increased customer satisfaction

- Inside competition of alliance partner

- Contract incompleteness

- Unfair exchange of resources and distribution of benefits

- Disagreement on alliance strategic objectives

- Opportunistic behaviors of mediators in risk management

- Low exit barrier and weak control by the parent company

- Cultural conflicts of alliance partners

- Improper internal communication of alliance partners

\section{Conceptual Framework}

Our framework stands upon an integration of the common alliance formation theories and perspectives, including TCT, RBV, KBV, inter-organizational theories, management and alliance formation stages. We believe success/failure factors should be sought out in the whole process (lifecycle) of an alliance. This approach, called the alliance formation perspective or the dynamic analysis model, has been used by previous researchers as well (e.g. Hoffman and Schlosser; 2001; Marxt and Link, 2002). They claim alliances should be studied in stages of initiation, partner selection, partnership creation, implementation and termination. Given the above, Hoffman and Schlosser (2001) derived 24 success factors.

In international alliances, cultural conflicts are central to the factors responsible for the alliances' failures (Sheng-Yue and $\mathrm{Xu}, 2005$ ). Thus, considering the earlier studies (e.g., Kumar and Andersen, 2000; Hughes and Weiss, 2007), as well as the Iranian pharmaceutical alliances, which are mainly international (Dadfar et al. 2013), the cultural factors influencing inter- 
organizational relationships were also considered. In total, 33 factors were derived from the reviewed theories and classified as content and process-orientated variables and theoretical sources (Tables 1 and 2, respectively).

This is an extension of the Hoffman and Schlosser framework from 24 to 33 success factors and includes both formation and orientation stages.

Table 1: Conceptual framework Content/process-orientated variables and alliance formation phases.

\begin{tabular}{|c|c|c|c|c|c|}
\hline Variables & Initiation & $\begin{array}{l}\text { Partner } \\
\text { selection }\end{array}$ & $\begin{array}{l}\text { Making } \\
\text { partnership }\end{array}$ & $\begin{array}{l}\text { Implementation/ } \\
\text { Partnership } \\
\text { management }\end{array}$ & Termination \\
\hline 惫 & $\begin{array}{l}\text { - High strategic } \\
\text { flexibility } \\
\\
\text { - Contributing } \\
\text { specific } \\
\text { strength and } \\
\text { looking for } \\
\text { similar } \\
\text { resources }\end{array}$ & $\begin{array}{l}\text { - Partner is } \\
\text { excellent in the } \\
\text { field of } \\
\text { cooperation } \\
\text { - Compatible } \\
\text { business strategy }\end{array}$ & $\begin{array}{l}\text { - Precise definition } \\
\text { of rights and } \\
\text { duties } \\
\text { - Equal } \\
\text { contributions of } \\
\text { all partners } \\
\text { - Emphasizing } \\
\text { joint value } \\
\text { creation } \\
\text { - Keeping their } \\
\text { own core } \\
\text { competencies }\end{array}$ & $\begin{array}{l}\text { - Establishing information } \\
\text { and coordination system } \\
\text { - Establishing required } \\
\text { resources } \\
\text { - Avoiding unwanted } \\
\text { transfer of knowledge } \\
\text { - Capacity to learn from } \\
\text { partner }\end{array}$ & $\begin{array}{l}\text { Preparing for } \\
\text { termination in } \\
\text { design phase }\end{array}$ \\
\hline 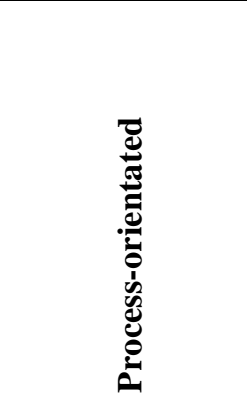 & $\begin{array}{l}\text { - Awareness of } \\
\text { time } \\
\text { requirement } \\
\text { - Development } \\
\text { of cooperation } \\
\text { culture } \\
\text { - Experience in } \\
\text { alliance } \\
\text { - Positive } \\
\text { attitude toward } \\
\text { alliance }\end{array}$ & $\begin{array}{l}\text { - Trust-based } \\
\text { relationship } \\
\text { - Agreements on } \\
\text { fundamental } \\
\text { values } \\
\text { - Commitment to } \\
\text { partnership } \\
\text { - Partner's } \\
\text { experience in } \\
\text { alliance }\end{array}$ & $\begin{array}{l}\text { - } \text { Avoiding } \\
\text { opportunistic } \\
\text { behavior } \\
\text { - Agreement on } \\
\text { clear objectives } \\
\text { - } \text { Making clear } \\
\text { action plan }\end{array}$ & $\begin{array}{l}\text { - Top management } \\
\text { support } \\
\text { - Speedy implementation } \\
\text { of measurement and fast } \\
\text { results } \\
\text { - Continual review of } \\
\text { alliance performance } \\
\text { - Creating team spirit } \\
\text { - Efficient conflict solving }\end{array}$ & $\begin{array}{l}\text { - Termination by } \\
\text { approval of all } \\
\text { partners } \\
\text { - Analyze the } \\
\text { cooperation as } \\
\text { a whole } \\
\text { - Learning about } \\
\text { risks, failure } \\
\text { and success } \\
\text { factors }\end{array}$ \\
\hline
\end{tabular}


Table 2: Conceptual framework: Success factors resulting from theoretical perspectives, categorized by alliance formation process and theoretical sources.

\begin{tabular}{|c|c|c|c|c|c|}
\hline $\begin{array}{l}\text { Theories } \\
\text { Success Factors }\end{array}$ & $\mathrm{TCT}^{*}$ & $\mathrm{RBV} * *$ & $\mathrm{KBV}^{* * *}$ & $\begin{array}{l}\text { Manage } \\
\text {-ment }\end{array}$ & $\begin{array}{l}\text { Inter- } \\
\text { organizational }\end{array}$ \\
\hline \multicolumn{6}{|l|}{ Decision making for cooperation } \\
\hline 1. High strategic flexibility & * & & & & \\
\hline $\begin{array}{l}\text { 2. Contributing specific strength and looking for } \\
\text { similar resources }\end{array}$ & & $*$ & & & \\
\hline 3. Deriving alliance objectives from business strategy & & & & $*$ & \\
\hline 4. Awareness of time requirement & & & & & $*$ \\
\hline 5. Development of cooperation culture & & & & & $*$ \\
\hline 6. Experience in alliance & & & & & * \\
\hline 7. Positive attitude to alliance & & & & & $*$ \\
\hline \multicolumn{6}{|l|}{ Partner selection } \\
\hline 8. $\quad$ Trust-based relationship & ** & & & & "* \\
\hline 9. Partner is excellent in the field of cooperation & & $*$ & & & \\
\hline 10. Compatible business strategy & $*$ & $*$ & $*$ & & \\
\hline 11. Agreements on fundamental values & & & & & * \\
\hline 12. Commitment to partnership & & & & & $*$ \\
\hline 13. Partner's experience in alliance & & & & & $*$ \\
\hline \multicolumn{6}{|l|}{ Designing the partnership } \\
\hline 14. Precise definition of rights and duties & * & & & & \\
\hline 15. Equal contributions of all partners & & $*$ & & & \\
\hline 16. Emphasizing joint value creation & & $*$ & & & \\
\hline 17. Keeping their own core competencies & & $*$ & $*$ & & \\
\hline 18. Avoiding opportunistic behavior & & & & & $*$ \\
\hline 19. Agreement on clear objectives & & & & $*$ & \\
\hline 20. Making clear action plan & $*$ & & & $*$ & \\
\hline \multicolumn{6}{|l|}{ Implementation and management of alliance } \\
\hline "21. Establishing information \& coordination system & * & & & & \\
\hline 22. Establishing required resources & & $*$ & & & \\
\hline 23. Top management support & & $*$ & & $*$ & \\
\hline 24. Avoiding unwanted transfer of knowledge & & & $*$ & & \\
\hline 25. Capacity to learn from partner & & & $*$ & & \\
\hline $\begin{array}{l}\text { 26. Speedy implementation of measurement and fast } \\
\text { results }\end{array}$ & & & & $*$ & \\
\hline 27. Continual review of alliance performance & & & & $*$ & * \\
\hline 28. Creating team spirit & & & & & $*$ \\
\hline 29. Efficient conflict solving & & & & & $*$ \\
\hline \multicolumn{6}{|l|}{ Termination of alliance } \\
\hline 30. Termination by approval of all partners & & & & & * \\
\hline 31. Preparing for termination in design phase & $*$ & & & & \\
\hline 32. Analyze the cooperation as a whole & & & & & * \\
\hline 33. Learning about risks, failure and success factors & & & & & $*$ \\
\hline
\end{tabular}

*Transaction cost theory, **Resource-based view, *** Knowledge-based view 


\section{Methodology}

First, we formed an expert panel of seven experts with extensive experience in pharmaceutical ISAs and related challenges in Iran. The panel helped us to create a general picture of the alliances' problems and opportunities, as well as to check the validity of the questionnaire. Considering the nature of the study and the expert panel's views, we used a combination of quantitative and qualitative methods in the data collection and analysis.

A questionnaire consisting of two parts (respondents' background, and 33 statements/questions) was used to collect quantitative data. Participants were asked to answer each question in the two dimensions of agreement and importance by using a Likert scale ranging from one to seven, where seven meant highest agreement/ importance and one meant lowest agreement/ importance.

The number of Iranian pharmaceutical managers involved in ISAs is very limited; therefore, the minimum sample size for the study was calculated by normal approximation to the "hyper-geometric" distribution (Hague, 2003). Accordingly, the minimum sample size required for this study was 73 participants; different managers with experience in alliances were included.

In total, 100 questionnaires were distributed among target managers, from which 79 useable ones were returned. The respondents' profiles were: CEOs (22\%), production managers (14\%), financial managers $(11 \%), \mathrm{R} \& \mathrm{D}$ managers $(8 \%)$, marketing managers $(13 \%)$, commercial managers $(10 \%)$, quality managers (11\%), business development managers (5\%), and general managers (6\%). Furthermore, $63 \%$ of respondents had 8-15 years of experience in the Iranian pharmaceutical industry, which seems experience enough to have good insights into the subject.

We used SPSS software for statistical analysis of quantitative data, and the overall reliability of the questionnaire value was acceptable (Cronbach's alpha $=0.89$ ). Nominal analytical tools and Freidman test were used to assess the effectiveness and to rank the success factors. We also ran gap analysis to identify the factors with the highest difference in perceived importance and the actual state of the alliances.

Qualitative data was gathered by 21 in-depth interviews consisting of 16 local/Iranian and five international managers involved in the Iranian pharmaceutical firms' SAs. The interviews and expert panel's views added substantial richness to the study.

\section{Results}

The results showed that the perceived rate of failed SAs was 27\%. However, the perception of the international partners' managers about failure rate was much higher $(60 \%)$ - they believed that three out of five cases of SAs in the Iranian Pharmaceutical industry have failed.

To find the success factors, the answers to the importance part of the questionnaire were analyzed by the binominal test. Answers 5, 6 and $7(>4)$ were assumed showing participants' acceptance of effectiveness of the considered factor, and answers to $1,2,3$ and $4(<=4)$ were assumed as rejection of the factor. The results showed that 31 factors were accepted by all participants (100\%) and the other two factors by $97 \%$ and $64 \%$, respectively. Hence, most of the respondents believed that all the chosen factors (33) were regarded acceptable as success factors.

After confirmation of all the success factors, they were ranked in terms of their perceived importance, as presented in Table 3. The eight factors with mean rank over 20 are considered as the most important (Table 3, Items 1-8).

Table 3 also shows the average gaps in rankings between agreement and importance rankings. When there is a big negative gap, it is a strong indication that the success factor has not been implemented successfully. More should be done to implement the success factors with the big negative gaps. When there are big positive gaps, it is a strong indication that the success factor has been well implemented. Such positive gaps may also indicate that the success factor has been implemented so well that the importance for further attention has decreased. So the focus for improvements, or better implementation of 
success factors, should be limited to the factors with big negative gaps. In the following sections, we will refer to those factors as failure factors.

The previous discussion indicates 11 failure factors which have the highest negative gaps (see Table 4). Interestingly, most of the failure factors (about $82 \%$ ) are content-orientated. This means the Iranian alliance managers are weak in the structuring, organizing and managing of SAs.

Table 3: Ranked success factors based on their importance and agreed (actual) state.

\begin{tabular}{|c|c|c|c|c|}
\hline \multirow[t]{2}{*}{ Item } & \multirow[t]{2}{*}{ Success Factors } & \multicolumn{2}{|c|}{ Mean Rank } & \multirow{2}{*}{$\begin{array}{c}\text { Gaps } \\
\text { A - I }\end{array}$} \\
\hline & & $\begin{array}{c}\text { Importance } \\
\text { (I) }\end{array}$ & $\begin{array}{l}\text { Agreed } \\
\text { (A) }\end{array}$ & \\
\hline 1 & Trust & 21.23 & 22.45 & 1.21 \\
\hline 2 & Establishing information \& coordination system & 21.04 & 15.55 & -5.49 \\
\hline 3 & Provide required resources & 21.02 & 21.72 & 0.70 \\
\hline 4 & Partner alliance experience & 20.82 & 17.19 & -3.63 \\
\hline 5 & Team spirit & 20.73 & 17.01 & -3.72 \\
\hline 6 & Agreement of values & 20.27 & 25.16 & 4.89 \\
\hline 7 & Developed cooperation culture & 20.23 & 18.80 & $-1,43$ \\
\hline 8 & Commitments of top management & 20.13 & 22.31 & 2.18 \\
\hline 9 & Capacity of learning & 19.66 & 19.96 & 0.30 \\
\hline 10 & Specific strengths of partners & 19.61 & 24.21 & 4.60 \\
\hline 11 & Commitment to partnership & 19.51 & 15.24 & -4.27 \\
\hline 12 & Time requirement & 19.49 & 19.37 & -0.12 \\
\hline 13 & Alliance experience & 19.21 & 17.19 & -2.02 \\
\hline 14 & Compatible business strategy & 18.80 & 14.53 & -4.27 \\
\hline 15 & Precise definition of rights and duties & 18.06 & 10.56 & -7.50 \\
\hline 16 & Continual review of alliance & 16.18 & 11.01 & -5.17 \\
\hline 17 & Equal contributions of all partners & 15.94 & 9.89 & -6.05 \\
\hline 18 & Learn from success or failure & 15.74 & 19.02 & 3.28 \\
\hline 19 & Contributing specific strength & 15.44 & 9.60 & -5.84 \\
\hline 20 & Termination condition & 15.42 & 22.26 & 6.84 \\
\hline 21 & Emphasizing joint value creation & 15.06 & 10.18 & -4.88 \\
\hline 22 & Avoiding unwanted transfer of knowledge & 15.03 & 14.73 & -0.3 \\
\hline 23 & Keeping their own core competencies & 15.02 & 9.54 & -5.48 \\
\hline 24 & High strategic flexibility & 15.01 & 9.36 & -5.65 \\
\hline 25 & Objectives from business strategy & 14.95 & 22.03 & 7.08 \\
\hline 26 & Clear objectives & 14.73 & 11.15 & -3.58 \\
\hline 27 & Positive attitude & 14.56 & 22.16 & 7.60 \\
\hline 28 & Efficient conflict solving & 14.36 & 22.44 & 8.08 \\
\hline 29 & Avoiding opportunistic behavior & 14.26 & 9.14 & -5.12 \\
\hline 30 & Termination approval & 13.97 & 19.79 & 5.82 \\
\hline 31 & Analyze the cooperation as a whole & 13.30 & 18.71 & 5.41 \\
\hline 32 & Clear action plan & 12.92 & 8.89 & -4.03 \\
\hline 33 & Speedy implementation & 9.33 & 17.01 & 7.68 \\
\hline
\end{tabular}

Table 4: Failure factors with highest gaps 


\begin{tabular}{|l|l|l|}
\hline & & variable \\
\hline \hline 1 & Precise definition of rights and duties & Content \\
\hline 2 & Equal contributions of all partners & Content \\
\hline 4 & Contributing specific strength & Content \\
\hline 5 & High strategic flexibility & Content \\
\hline 6 & Establishing information \& coordination system & Content \\
\hline 7 & Keeping their own core competencies & Content \\
\hline 8 & Continual review of alliance performance & Process \\
\hline 9 & Empoiding opportunistic behavior & Process \\
\hline 10 & Compatible business strategy & Content \\
\hline 11 & Commitment to partnership & Content \\
\hline \hline
\end{tabular}

Comparing the eight most important success factors with Table 2 confirms that most $(75 \%)$ of the factors having outstanding effects on the success of Iranian pharmaceutical alliances are process-orientated variables, as presented in Table 5.

Table 5: Eight most important success factors in pharmaceutical companies' alliances in Iran

\begin{tabular}{||l|l|l|l||}
\hline Ranks & Success Factors & Mean rank & Kinds of Variables \\
\hline \hline 1 & Trust & 21.23 & Process \\
\hline 2 & Establishing information \& coordination system & 21.04 & Content \\
\hline 3 & Provide required resources & 21.02 & Content \\
\hline 4 & Partner alliance experience & 20.82 & Process \\
\hline 5 & Team Spirit & 20.73 & Process \\
\hline 6 & Agreement on fundamental values & 20.27 & Process \\
\hline 7 & Developed cooperation culture & 20.23 & Process \\
\hline 8 & Commitment of top management & 20.13 & Process \\
\hline
\end{tabular}

\section{Qualitative Analysis}

The qualitative analysis helped to go deeper into understanding the success/failure situation in Iranian pharmaceutical ISAs. Some of the important points derived from the interviews were:

- Each SA is unique, requiring its own mix of talents, knowledge, resources and capabilities.

- SA success/failure must be seen from both parties' lens. Evaluating alliances from just one side could be misleading.

- Very often, the success (win) of one partner does not necessarily mean success (win) for another. A strategic alliance is regarded as fully successful only if both parties' perceive it as a success.

- Lack of continuous open and honest communication causes major drawbacks in the alliance.

- Without a "win-win" attitude, you should not expect any success in any type of alliance. 
- Some partners are unwilling to compromise.

- Some partners are not as technically competent as they claim, nor do they contribute what they have promised.

- Technical knowledge, social competence and long-term profit seeking are of the necessary attributes for success.

- Effective communication is the most important critical success factor in ISAs

- Mutual trust, mutual understanding, and building common values lead to mutual success.

- In developing countries, the role of the local government should not be underestimated in the success of alliances.

- Each partner has its own distinct objectives, which if not compatible with other partners, may lead to conflict.

- There is a lack of conformity between expected and actual contribution of the parties. For example, the local partners, especially in public sectors, expected the other party to share his technological and managerial knowledge with them. Once the local partner feels that proper technology transfer is not taking place, he begins to mistrust the other party. Very often, the foreign partner is accused of a lack of willingness for technology transfer and fulfillment of the agreement.

- Good knowledge of each other's business culture, working attitudes, and the preferred way of getting things done is a powerful success factor.

- Success can mean different things to different people/firms.

- Multinational managers' views:

- Iranians are too optimistic or too pessimistic, and find it hard to accept reality.

- Cultural awareness, good communication, being clear with tasks and each partner taking responsibility are musts.

- A certain form of alliance management successful in one country may not be successful in another; each country requires a specific approach.

- In Iran, it is very common to blame foreign partners for failures; it is sometimes difficult to make them understand that the causes are something else.

- Very often the parties have different views on the success and failure of the alliance. For example, three cases that Iranians evaluated as a success were a failure for the international partners. This is because Iranians were looking for technology rather than profit, while the foreign partners aimed at increasing their market share and profit.

\section{Discussion and conclusion}

\section{The Most Important Success factors in Iranian Pharmaceutical Alliances}

This study set out to identify the key factors that determine the success/failure of ISAs in the Iranian pharmaceutical industry. The research framework used has been built upon five theoretical perspectives, from which 33 success factors were identified. The factors, combined with alliance formation stages as well as process and content dimensions, constitute our theoretical and conceptual framework (Tables 1 and 2). The results of the binominal test for the effectiveness of the identified factors confirmed that all 33 factors were regarded as effective. This is an extension to earlier frameworks with "only" 24 factors. 
The results revealed 8 important success factors with mean ranks over 20 (Table 3). Comparing the perceived and actual mean ranks resulted in the following eight, very important success factors (Table 5):

1. Agreement on fundamental values. 2. Partners' previous alliance experiences. 3. Building a trust-based relationship. 4. Top management commitment. 5. Providing the required resources for formation of ISAs. 6. Developing a cooperative culture. 7. Developing team spirit. 8. Establishing information \& coordination systems.

Interestingly, most of the success factors are process-oriented (see Table 5).

Qualitative data supports the quantitative results and adds the most successful factors as a winwin attitude, mutual trust, creating common value, compatibility of partner's objectives, good knowledge of each others' business culture, and each alliance must be perceived unique.

The results showed that the partners' mutual understandings, their agreement on common basic values, previous alliance experiences, honesty, management's positive attitude and their commitment as well as support to the relationship, and finally on-time and complete provision of agreed resources are most important for a successful co-operation (see Tables 1, 2 and 3). These findings support the earlier studies (e.g. Fontanari, 1995; Marxt and link, 2002; and Sheng- Yu and $\mathrm{Xu}, 2005$ ), and contribute nine extra determinants. The results also support the earlier studies emphasizing a collaborating culture and avoiding a blaming culture (Dadfar, Brege, 2012; Dadfar, et al. 2013).

Trust, with a mean rank score of 21.23, is central to relationship building in ISAs; this factor should be seriously considered in the second phase of searching for a partner. Furthermore, the highest importance factors $(21.04,21.02,20.73$, and 20.82) are information and coordination system, resource providing, past experience and team spirit. Besides, the parties must have an open mindset, a win-win attitude, and flexibility; contributing what has been promised, and top managements' commitment/support, is also crucial.

The firms should look for a proper partner with complimentary capabilities and resources. The partner's objectives and interests should be compatible to avoid a conflict of interest. It is preferable to find a partner that is a good cultural fit; however, cultural conflicts between organizations from different countries are inevitable. The partners with experience from previous alliances will be more flexible in cooperation and more aware of such conflicts. Showing commitment to the partnership (score 20.13) and being honest, as well as building a trust-based relationship (score 21.23), are at the heart of inter-organizational collaboration. Likewise, agreement on basic common values (score 20.27), and reaching a common understanding should be developed during the SA formation /second phase.

Furthermore, partners' tasks, duties, and (resource) contribution should be defined and clearly agreed upon. As one of the objectives of alliances is learning, partners should help each other to enhance their leaning ability. The results confirmed that an information and coordination system should be established for proper partner connection.

The termination phase also has its own conditions. The termination conditions should be described in the written agreement, and the partners should decide to finish the cooperation by a mutual agreement. If a partner terminates an alliance unilaterally, it is considered as untrustworthy. 
After finalizing the collaboration, it is crucial that the alliance's performance (indicating the values and competencies gained or possible problems and costs occurred) is evaluated. Learning from successful/failed alliances and the factors which caused success or failure should be identified.

The results confirm that six of eight very important success factors are process-orientated variables; thus, developing an inter-organizational relationship, building trust and mutual understanding issues are particularly important in establishing successful ISAs in Iran.

\section{Failure Factors in Iranian Pharmaceutical Alliances}

The gap analysis indicated 11 factors causing the alliances' failures (Table 4). For example, the lack of a precise definition of rights and duties, followed by opportunistic behaviors, may lead to conflict/failure. The unequal partners' contribution is the second main reason for failure. Many of the alliances also failed because of a lack of strategic flexibility. Indeed, it is impossible to do any business without having enough flexibility in Iran's turbulent business environment. Furthermore, a lack of compatibility with the partners' objectives may lead to conflict/failure.

Some of the alliances failed due to forgetting the nature of a SA, which is cooperation for making shared values for both partners. Dishonesty, looking for short-term goals, and having an egocentric opinion may disturb the inter-organizational collaboration. The interviews also clearly confirmed that the failed alliances are due to a lack of commitment to the partnership. Therefore, not solving common cultural misunderstandings and the absence of mutual trust pushed the alliances to an improper ending.

Unexpectedly, 8 of 11 failure factors were content-orientated variables, which clarify that most failed Iranian alliances have difficulties in strategic and structural design. That is, an alliance with improper structural design will most likely fail in Iran.

The results of the interviews confirm the above findings and add:

- An alliance can be conceived as a socio-technical system; thus, both hard and soft issues are important.

- Each strategic alliance is unique, and partners must understand the uniqueness of the alliance and its management. The term "success" may mean different things to different people. Thus, partners should develop criteria that both consider as key success factors.

- The results of interviews indicate that an alliance may be perceived as a success by one party and a failure by another. Therefore, the overall alliance success or failure should not be seen as black or white. By considering the parties' perception of success and failure, four situations may occur as presented in Figure 1, and may change over time. 


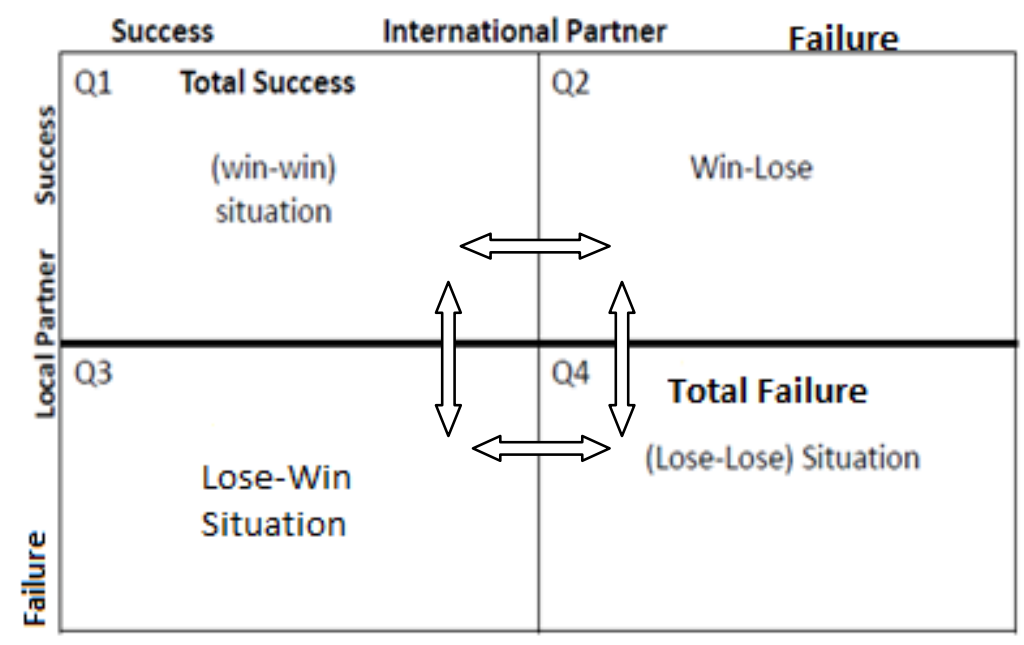

Fig. 1: Success/failure situation in international alliances

Q1 is the best situation; both parties feel success. In this situation, the parties were working together for an intensive period (over 10 years) and had built trust and mutual understanding and respect as well as a collaborative culture in their organizations. The parties' strategies and objectives fit well together. Both partners perceived the eight success factors as very important, and conceived the SA as socio-technical marriage in which both social and technical aspects are important. In Q2, the local partner feels success but the international partner feels failure (e.g., the local partner had access to technology but the foreign partner did not get their expected market share). In this situation, the parties' objectives were not compatible; one party perceived the other party's behavior as opportunistic, while the international partner believed that the local partner had not done what they promised to do. The atmosphere of mistrust weakened the relationship; if managers do not solve such problems and create trust, it may develop into a Q4 situation. In Q3, the local partner feels failure and complains but the international partner feels success (e.g. inadequate technology transfer); this situation is similar to that of Q2, and if not properly managed may develop into the worst situation (Q4). In both Q2 and Q3 situations, the SAs were rather young and their lifetime was under 5 years. Q4 represents a total failure, because both parties view the cooperation as a failure. The lack of clear mutual trust, the lack of cultural awareness and effective communication, as well as local governments, who directly or indirectly influence SAs through, for example, changing tariffs, quotas and sanctions, were wellevidenced in this situation. In a Q4 situation, accusing each other for failures is common among the partners. In this quadrant, both parties had chosen a short-term profit orientation and opportunistic behavior.

In summary, the current study unveils that:

- All 33 identified factors are effective in the alliances' success; this finding is an extension to the earlier frameworks with only 24 factors. The results enhance our understating of international alliances' complexity, the importance of soft issues and the necessity of including both parties' views. 
- The second major finding was the eight most important success factors and eleven most important failure factors in Iranian pharmaceutical industry SAs. Furthermore, the results show that most of the success factors are process-oriented, while most of the failure factors are content-oriented. This means that the successful alliances were good in building the alliances, and most of the failed alliances had difficulties with strategic and structural design of the alliances.

- It was also shown that various alliance formation stages have different weights in the alliances' success; e.g., the partner-searching phase and the implementation/management phase are the most important, having the most contribution to the alliances' success. Conversely, the termination phase had the least contribution to the alliances' success.

- The term "success" can mean different things to different people/partners. Thus, an alliance perceived as a success by one party may be perceived as failure by another. Therefore, the success and failure studies in SAs that stand on data from only one party are challenged for providing only a partial picture of reality.

- This study found four success/failure situations (Fig. 5.1). So far, the studies have been focused on only two situations (Q1, Q4), while the other two situations (Q2, Q3) have remained unexplored.

- More research is needed to better understand the strategic alliances' four success/failure situations and relevant determinant factors.

- A future study investigating an extended framework (33 success/failure factors) in the context of other industries and countries would be very interesting.

\section{References}

ASAP (2012). The Fourth State of Alliance Management Study, Association of Strategic alliance Professionals.

Chung, S., Singh, H. and Lee, K. (2000). Complementarity, status similarity and social capital as drivers of alliance formation, Strategic Management Journal 211-22.

Cravens, K., Piercy, N., and Cravens, D. (2000). Assessing the performance of strategic alliances: matching metrics to strategies', European Management Journal, 18 (5), 529-541

Dadfar, H. and Brege, S. (2012). Differentiation by improving quality of services at the last touch Point, International Journal of Quality and Service Sciences, Vol. 4 Iss: 4 pp. $345-363$.

Dadfar, H., Dahlgaard J. Brege, S and Alamirhoor, A (2013) Linkage between Organizational Innovation capability, product platform development and performance: The case of pharmaceutical SMEs in Iran. Journal of Quality Management\& Business Excellence, Volume 24 issue 5,

Das, T. K. and Teng, B. (2000a). A resource-based theory of strategic alliances. Journal of Management, 26 (1), 31-61.

Das, T. K. , and Teng, B.S (2000b). Instabilities of Strategic Alliances: An Internal Tensions Perspective. Organization Science, 11(1), 77-101.

de Man, A. P. and Duysters, G. M. (2007). The Second State of Alliance Management Study. Association of Strategic alliance Professionals.

Dussauge P. and Garrette B., (2000), Learning from competing partners: Outcomes and durations of scale and link alliances in Europe, North America and Asia, Strategic Management Journal, 21 (4), 99-126

Duysters, G., De Man, A.P; and Wildeman, L. (1999). A network approach to alliance management, European Management Journal 17 (2), 182-187.

Dyer, J. H. \& Singh, H. (1998). The relational view: cooperative strategy and sources of interorganizational competitive advantage. Academy of Management Review, 23 (4), 660-679. 
Eisenhardt, K. M., \& Schoonhoven, C. B. (1996). Resource-Based view of strategic alliance formation: strategic and social effects in entrepreneurial firms. Organization Science, $7(2), 136-150$.

Fontanari, M. (1995). Conditions for successful cooperation; an empirical study. Management of Joint Ventures, Ueberreuter, Wien.

Gilmore, A.; Carson, D., and Rocks, S. (2006). Networking in SMEs, evaluating its contribution to marketing activity, International Business Review, 15, 278-293.

Glaister, K.W. (1996). UK-Western European strategic alliances: motives and selection criteria. Journal of Euro-marketing, 54(4), 5-35.

Grant, R. M. and Baden-Fuller, C. (2004). A knowledge accessing theory of strategic alliances. Journal of Management Studies, 41(1), 61-84.

Hague, P. (2006). A practical guide to marketing research, Grosvenor House Publishing Ltd.

Hitt, M.A., Dacin, T.M., Levitas, E., Arregle, J.L. and Borza, A. (2000). Partner selection in emerging and developed market contexts: Resource-based and organizational learning Perspectives, Academyof Management Journal 43(3): 449-467.

Hoffmann, W. and Sclosser, R. (2001). Success factors of strategic alliances in Small and Medium Sized Enterprises: An empirical survey. Long Range Planning, 34, 357-381.

Hughes, J. and Weiss, I. (2007). Simple Rules for Making Alliances Work, Harvard Business Review, 85 (November), 122-31.

Judge, W. D. and Dooley, R. (2006). Strategic alliance outcomes: A transaction cost economic perspective. British Journal of Management, 17, 23-37.

Kumar, R. and Andersen, P.H. (2000). Inter firm diversity and the management of meaning in international strategic alliances, International Business Review 9(2): 237-252.

Marxt, Ch. And Link, P. (2002). Success factors for cooperative ventures in innovation and production systems. International Journal of Production Economics, 77, 219-229.

Mort, G.S. and Weerawardena, J. (2006). Networking capability and international entrepreneurship: How networks function in Australian born global firms. International Marketing Review, 23(5), pp.549-572.

Perlmutter, R.V., and Heenan, D.A., (1986). Co-operate to compete globally, Harvard Business Review, 136-150.

Phan, P.H. (2000). Knowledge creation strategic alliance: Another look at organizational learning. Asia Pacific Journal of Management. 2000, 12: 201-222.

Porter, M.E. (1990). The Competitive Advantage of Nations, Free Press, New York.

Prahalad, C.K., \& G. Hamel, (1990). The Core competence of the corporation, Harvard Business Review, , May-June, 79-91.

Root, F. R., (1988). Some taxonomies of international cooperative arrangements; cooperative strategies in international business," 69-80, Edited by: Contractor, F. J. and Lorange, P., New York: Praeger International Series.

Sheng-yu, H. and Xu, R. (2005). Analysis of strategic alliance failure: A aynamic model. International Conference of Management Science and Engineering, Beijing, China.

Townsend, J. D. (2003). Understanding alliances: a review of international aspects in strategic marketing, Marketing Intelligence \& Planning, [online], Vol. 21, No. 3.

Tsang, E. W. (1998). Motives for Strategic Alliance: A Resource-Based Perspective. Scandinavian Journal of Management, 14 (3), 207-221.

Yasuda, H. (2005). Formation of Strategic Alliances in high-technology industries: comparative study of the resource- based theory and the transaction-cost theory. Technovation, 25, 763-770 